\title{
FATORES DE ATRATIVIDADE: ABORDAGEM SEDUTORA PARA CONQUISTAR INGRESSOS NO CURSO DE SECRETARIADO EXECUTIVO
}

\section{ATTRACTIVENESS FACTORS: SEDUCTIVE APPROACH TO CONQUER FRESHMEN IN THE EXECUTIVE SECRETARIAT COURSE}

\section{Ana Karina Reis}

Bacharel em Secretariado Executivo Trilíngue pela Universidade Federal de Viçosa - UFV E-mail: anakarinareis@hotmail.com (Brasil)

\section{Ane Grasiele Gomes de Freitas}

Mestre em Administração pela Universidade Federal de Lavras - UFLA

Secretária Executiva na Universidade Federal de Ouro Preto - UFOP

E-mail: ane_grasiele@yahoo.com.br (Brasil) 


\title{
FATORES DE ATRATIVIDADE: ABORDAGEM SEDUTORA PARA CONQUISTAR INGRESSOS NO CURSO DE SECRETARIADO EXECUTIVO
}

\section{RESUMO}

A profissão de Secretariado Executivo tem se destacado no Brasil e no mundo. As Instituições de Ensino Superior - IES precisam estar preparadas para acompanhar as tendências em virtude do crescimento e contínuo reconhecimento da profissão secretarial, com intuito de capacitar e qualificar os alunos para desempenharem suas funções no mercado de trabalho. Partindo do pressuposto de que estratégias de comunicação são meios de persuadir o público-alvo e determinar atitudes, desenvolveu-se uma pesquisa qualitativa baseada em entrevistas em profundidade com graduandos e análise de conteúdo dos discursos para identificar os fatores de atratividade do curso de Secretariado Executivo Trilíngue da Universidade Federal de Viçosa, MG. Como contribuições, a discussão analítica embasou o delineamento de características importantes para subsidiar a comunicação de marketing da coordenação para atrair estudantes para o curso, por meio da compreensão da comunicação como instrumento de divulgação das atividades e dos desafios para os estudantes e os profissionais da área.

Palavras-chave: Secretariado Executivo; Fatores de Atratividade; Comunicação de Marketing; Graduação.

\section{ATTRACTIVENESS FACTORS: SEDUCTIVE APPROACH TO CONQUER FRESHMEN IN THE EXECUTIVE SECRETARIAT COURSE}

\begin{abstract}
The profession of the Executive Secretariat has gained prominence in Brazil and worldwide. The Higher Education Institutions must be prepared to follow the trends due to the growth and continued recognition of the secretariat profession, in order to train and qualify students to perform their functions in the labor market. Assuming that communication strategies are means to persuade the target audience and determine attitudes, qualitative research was based on interviews with graduates and satisfaction analysis of transcripts to identify the factors of attractiveness of Trilingual Executive Secretariat course at Universidade Federal de Viçosa. As contributions, analytical discussion served as basis for the delineation of important features to support the coordination of marketing communications to attract students to the course, through the understanding of communication as a tool for dissemination of activities and challenges for students and professionals.
\end{abstract}

Keywords: Executive Secretariat; Attractiveness Factors; Marketing Communication; Undergraduate Program. 


\section{INTRODUÇÃO}

O surgimento da profissão do Secretário é incerto e, ao longo da história várias figuras exerceram atividades que se assemelhavam às tarefas executadas pelos profissionais de secretariado, as quais, com o tempo, aperfeiçoaram-se e adaptaram-se à profissão.

Economicamente atrativa, não só pela abrangência no campo de conhecimento como também pela empregabilidade, a área está envolta de características de multiplicidade e diversidade, exigindo iniciativa e criatividade dos profissionais sob a ótica educativa e informacional. O perfil deste profissional está ligado à qualificação multifuncional, dada a exigência da capacidade de transitar entre competências de campos diferentes. Marchelli e Sabino (2009, p. 607) caracterizam o Secretário Executivo como:

\footnotetext{
Um assessor pessoal, que tem entre suas atribuições a tarefa de organizar as rotinas de líderes atuantes nas empresas ou em outras formas de organização, valendo-se fundamentalmente da ciência administrativa, que constitui o entorno conceitual básico para o desenvolvimento das tarefas que lhe são pertinentes.
}

Sob esta perspectiva, a promulgação da nova Lei de Diretrizes e Bases da Educação - LDB, em 1996; a institucionalização do Exame Nacional do Ensino Médio - Enem; e, a criação do programa de Reestruturação e Expansão das Universidades Federais - Reuni, modificaram o modelo educacional do País, em consonância com a demanda de qualidade do ensino superior para atender à competitividade e ao dinamismo do mercado de trabalho (Koc, 2006). O Catálogo de Graduação da Universidade Federal de Viçosa - UFV apresenta as características do curso de Secretariado Executivo Trilíngue, curso que permite ao graduado o exercício pleno da profissão, nos termos definidos pela lei de regulamentação.

As mudanças no perfil dos secretários executivos fazem com que as Instituições de Educação Superior - IES tenham de se preocupar em preparar e capacitar os alunos em consonância com as tendências de mercado, em virtude do crescimento e contínuo reconhecimento da profissão. A problemática deste estudo surge da necessidade de se elaborar estratégias de comunicação para atrair estudantes, as quais podem ser desenvolvidas em virtude da compreensão dos motivos pelos quais os ingressantes escolhem o curso de graduação.

Partindo-se do pressuposto de que estratégias de comunicação projetadas são meios de persuadir e conseguir efeito nas atitudes do público-alvo (Pinho, 2001), teve-se como proposta a identificação dos fatores de atratividade do curso de Secretariado Executivo Trilíngue da UFV, a fim de subsidiar a comunicação de marketing da coordenação a fim de atrair estudantes para o

Revista de Gestão e Secretariado - GeSec, São Paulo, v. 5, n. 1, p 42-61, jan./abr. 2014. 
curso. Acredita-se que os fatores de atratividade possam contribuir para reformulações na grade curricular e para o desenvolvimento de estratégias de comunicação da imagem positiva do curso, com o objetivo de captar mais candidatos. Este construto é apontado por Ikeda e Veludo-deOliveira (2005) enquanto possibilidade de aplicação de ferramentas de marketing como aporte para o desenvolvimento de práticas e técnicas na promoção positiva da imagem.

A pesquisa qualitativa baseou-se em entrevistas em profundidade com alunos, tendo sido adotada como método a análise de conteúdo. Ela visou identificar os fatores de atratividade do curso de Secretariado Executivo Trilíngue da Universidade Federal de Viçosa. Pretendeu-se obter informações mais recentes (2008 a 2010), que servissem de suporte para a reflexão ampla sobre o assunto. Com as técnicas para coleta de dados, resgatou-se a trajetória pessoal e estudantil dos alunos, procurando, na sequência, analisar os discursos e compreender as interpretações acerca de sua inserção no curso, seguido pelas considerações finais para prover informações relativas aos fatores atrativos para futuros programas de comunicação de marketing.

\section{REFERENCIAL TEÓRICO}

\subsection{A PROFISSÃO E O CURSO DE SECRETARIADO}

O conhecimento da profissão de Secretariado, embora confuso em alguns pontos da história, faz-se importante para a compreensão de como ocorreu sua evolução e seu reconhecimento. Acredita-se que os escribas foram os primeiros secretários da história, os quais dominavam a escrita, redigiam e arquivavam documentos, colocados a serviço da administração real e sacerdotal (Marrou, 1975).

Inicialmente, a profissão era exercida pelos homens, mas com o advento das duas guerras mundiais, as mulheres começaram a atuar de forma expressiva como secretárias, principalmente na Europa e nos Estados Unidos, devido à escassez de mão de obra masculina direcionada para os campos de batalha. No Brasil, aumentou-se a demanda dos cargos de secretária com a chegada das multinacionais em meados de 1950. Contudo, o grande avanço e marco para a profissão ocorreram na década de 1970, em que significativas mudanças configuraram as secretárias como membros ativos na gerência, dotadas de respeito nas organizações. Moraes (2005) complementa que, seguindo uma trajetória que começou nas últimas décadas na carreira destes profissionais, ficam

Revista de Gestão e Secretariado - GeSec, São Paulo, v. 5, n. 1, p 42-61, jan./abr. 2014. 
evidentes as iniciativas que possam ampliar as áreas de atribuição no mundo do trabalho e tornar as carreiras cada vez mais complexas e especializadas.

Nas Diretrizes Curriculares Nacionais instituídas pelo Ministério da Educação (MEC), a formação deste profissional deve contemplar conteúdos básicos, específicos e teórico-práticos. $\mathrm{Na}$ Universidade Federal de Viçosa, Secretariado Executivo Trilíngue foi implantado como uma habilitação do curso de Letras, sendo reconhecido como curso superior em 2003 pelo Ministério da Educação.

A cada ano, os cursos superiores de secretariado crescem em todos os estados brasileiros, e, atualmente, há pelo menos um curso em cada Unidade da Federação. O Programa de Apoio a Planos de Reestruturação e Expansão das Universidades Federais (Reuni) é parte do processo de expansão da educação superior no Brasil.

Com a otimização e o crescimento das instituições de ensino no país, saber como atrair os estudantes tem sido fundamental. Em face às mudanças ocorridas no ensino brasileiro, decidir o curso e as instituições para a realização das provas do vestibular está cada vez mais complexo para os vestibulandos. O Guia do Estudante da Editora Abril e O Guia das Profissões fornecem informações sobre o curso de Secretariado Executivo caracterizando-se como influentes fontes de consulta.

As instituições que aderiram ao programa Reuni receberam financiamentos para o aumento do número de vagas e de cursos, de forma que essa nova política educacional tem influenciado positivamente a representatividade do curso na UFV: no meio acadêmico, há a disseminação das informações sobre o curso no próprio campus, na comunidade e na região; no campo profissional, visa-se o aumento da competitividade de mercado e ao reconhecimento pelos avanços na área.

Nesse sentido, a instituição entrega valor aos seus clientes por meio do serviço prestado. A entrega de valor se dá por meio de trocas, conforme necessidades e desejos dos consumidores (Kotler \& Keller, 2006). Os serviços educacionais são oferecidos pelas universidades, sob a ótica de que os clientes são os ingressos no curso.

O resgate do histórico pessoal e estudantil dos respondentes possibilitou essa compreensão da relação entre a universidade e seu público e a identificação dos fatores que atraem os alunos para o curso de Secretariado Executivo Trilíngue da UFV, com apreensão mais assertiva da realidade dos acadêmicos e das variáveis importantes para atraí-los.

Não obstante, para identificação de possíveis fatores de atratividade do secretariado é necessário abordar os aspectos da atual dinâmica do conhecimento científico da área. Hoeller (2006, p. 144) explica que "o curso de Secretariado Executivo não é uma ciência no sentido conhecido [...],

Revista de Gestão e Secretariado - GeSec, São Paulo, v. 5, n. 1, p 42-61, jan./abr. 2014. 
mas sim um campo de estudo de aplicação" e afirma que

[...] o curso está na área da ciência factual, utiliza-se do método indutivo, no campo social área de humanas, proveniente de várias ciências puras como: direito, economia, política, sociologia, linguística $[s i c]$ e outras [...].

Os estudos de Marchelli e Sabino (2009) explicam que para realização de estudos, os pesquisadores têm utilizado subsídios epistemológicos de várias ciências para a abordagem teórica. Apresentam-se a seguir fatores de atratividade definidos em pesquisas de áreas afins, recorrendo-se aos seus resultados para alicerçar a construção teórica do secretariado.

\subsection{FATORES DE ATRATIVIDADE}

Deschamps, Domingues e Mainardes (2008) afirmam que as escolas do ensino médio são as responsáveis por encaminhar os alunos às universidades e faculdades, de modo que não se devem negligenciar as ligações existentes entre o ensino secundário e o superior.

Outro fator atrativo abordado é a imagem da instituição de ensino (Franco, 2000; Palacio; Meneses \& Pérez, 2002; Bronemann \& Silveira, 2004; Becker, Fornoni, Perfeito \& Silveira; 2004; Deschamps; Domingues \& Mainardes, 2008). Para se falar de eficiência no âmbito educacional, deve-se atentar às atividades, ações, estratégias, aos serviços e processos desenvolvidos para reforçar a imagem de uma entidade universitária, a qual tem influência considerável sobre os consumidores e pode ser considerada como fator decisivo na aquisição de produtos ou serviços. A imagem é construída por meio de várias fontes, sendo a publicidade uma importante ferramenta no seu processo de construção (Pinho, 2001).

Franco (2000), Palacio, Meneses e Pérez (2002) elucidam que a marca da instituição é um fator de atração para os estudantes, os quais procuram por instituições competentes e renomadas. No Exame Nacional de Desempenho de Estudantes (Enade), realizado em 2006, o curso de Secretariado Executivo Trilíngue da UFV foi apontado como o melhor do país, em segundo lugar na classificação geral de todas as áreas avaliadas. Desta forma, a imagem que o estudante transmite da universidade que frequenta influencia significativamente a atração de novos alunos (Palacio; Meneses \& Pérez, 2002).

Hides, Davies e Jackson (2004) afirmam ainda que as melhores práticas pedagógicas e a satisfação dos clientes são importantes fatores de excelência dos serviços para construir a imagem da instituição. A diversidade de disciplinas oferecidas no curso de Secretariado Executivo implica 
uma análise sobre os idiomas.

Com a redução dos obstáculos e das fronteiras entre os países, as pessoas mais bem informadas e atualizadas serão peças-chave nas empresas (Maccari, Martins, Terra \& Vicente, 2010). Ao oferecer uma formação acadêmica na modalidade trilíngue, o curso da UFV pode assim apresentar outro construto atrativo na visão do aluno, enquanto serviço educacional oferecido pela instituição, detectado também como fator atrativo por Bronemann e Silveira (2004).

Nas pesquisas de Bronemann e Silveira (2004) foi observado que a satisfação dos veteranos e o contato com eles foi fator atrativo para os estudantes em relação ao curso. Corroborando com esta afirmação, Kotler e Keller (2006) afirmam que as fontes pessoais de informação do consumidor são as mais efetivas, já que desempenham uma função de avaliação e legitimação. A influência dos familiares e amigos como fator na escolha teve maior representação em um número maior de pesquisas, dentre elas as de Maccari (2010), Becker et al. (2004) e Bronemann e Silveira (2004).

Para Pereira e Forte (2006) a inovação também se apresenta como construto (fator) atrativo para os alunos. Deschamps, Domingues e Mainardes (2008) explicam que esse requisito contribui para a disseminação do conhecimento com foco no desenvolvimento de criações capazes de serem utilizadas para melhorar a imagem e orientar a organização para o mercado.

A empregabilidade e a compreensão do mercado de trabalho foram construtos que influenciaram as escolhas dos estudantes nos estudos realizados por Pereira e Forte (2006), Bronemann e Silveira (2004), Deschamps, Domingues e Mainardes (2008). Alfinito e Granemann (2003) ressaltaram que o apreço dos alunos delimitou-se nos seguintes fatores: proximidade de casa ou do trabalho, infraestrutura e instalações, horários disponíveis das disciplinas, método de ensino e segurança no campus.

Por fim, os fatores realização profissional, qualidade da biblioteca, facilidade na obtenção de estágios, conceituação perante o MEC e reputação do curso foram identificados nos trabalhos de Bronemann e Silveira (2004), Becker et al. (2004) e Deschamps, Domingues e Mainardes (2008).

\subsection{O PROCESSO DE COMUNICAÇÃO}

A comunicação mercadológica (Quadro 1), projetada para ser persuasiva nas atitudes e no comportamento do público visado, é realizada por meio de várias modalidades.

Revista de Gestão e Secretariado - GeSec, São Paulo, v. 5, n. 1, p 42-61, jan./abr. 2014. 


\begin{tabular}{|c|l|c|}
\hline MODALIDADE & \multicolumn{1}{|c|}{ CARACTERÍSTICAS } & \multicolumn{1}{|c|}{ FERRAMENTAS } \\
\hline Publicidade & $\begin{array}{l}\text { O serviço, produto ou negócio é divulgado por } \\
\text { meio de notícias em mídia impressa, rádio, } \\
\text { televisão, entre outros. }\end{array}$ & $\begin{array}{l}\text { Anúncio impresso e eletrônico; } \\
\text { folhetos e catálogos; placas e } \\
\text { letreiros; símbolos e marcas. }\end{array}$ \\
\hline Relações Públicas & $\begin{array}{l}\text { O bom relacionamento com o público por meio da } \\
\text { comunicação estimula a opinião favorável à } \\
\text { instituição/curso. }\end{array}$ & $\begin{array}{c}\text { Palestras; seminários; publicações; } \\
\text { relações com a comunidade; eventos. }\end{array}$ \\
\hline Marketing Direto & $\begin{array}{l}\text { Estratégia de comunicação de produtos ou serviços } \\
\text { com o cliente, sem intermediação de meios e } \\
\text { canais de terceiros. }\end{array}$ & $\begin{array}{l}\text { Catálogos; mala-direta; } e-m a i l ; \\
\text { panfletagem; "boca a boca”. }\end{array}$ \\
\hline Propaganda & $\begin{array}{l}\text { Mensagem para persuadir o cliente a utilizar o } \\
\text { serviço paga pela própria organização ou por } \\
\text { terceiros, por tempo limitado ou não. }\end{array}$ & $\begin{array}{c}\text { Espaço em jornais, revistas; televisão; } \\
\text { páginas de pesquisa na internet. }\end{array}$ \\
\hline
\end{tabular}

Quadro 1- Modalidades de Comunicação de Marketing. Fonte: Adaptado de Kotler (2009); Pinho (2001).

Para melhor consolidação do conhecimento sobre a existência do curso de Secretariado Executivo da UFV, é possível utilizar as modalidades de comunicação de marketing para divulgar positivamente a imagem do curso e atrair os ingressos. De acordo com cada estratégia de divulgação, é necessário avaliar quais ferramentas são adequadas (Pinho, 2001).

Ao publicar notícias em jornais, revistas e divulgar na mídia televisiva as informações atrativas do curso da UFV por meio da propaganda e da publicidade, por exemplo, pode-se influenciar um número cada vez maior de vestibulandos, não só da região como também de outros estados. A distribuição direta de panfletos, o incentivo ao marketing "boca-a-boca" e a seleção de locais apropriados para fixação de letreiro são iniciativas que podem demandar menor complexidade para serem colocadas em práticas, podendo ser, a princípio, mais favoráveis e propícias para utilização.

Ressalta-se a importância da Internet e de seu uso adequado nos processos de comunicação atuais, uma vez que o crescimento exponencial do número de seus usuários a define como um influente meio de comunicação. Deste modo, percebe-se que esta é mais uma ferramenta que pode ser útil para atrair alunos para o curso de Secretariado Executivo Trilíngue da UFV, por meio de

Revista de Gestão e Secretariado - GeSec, São Paulo, v. 5, n. 1, p 42-61, jan./abr. 2014. 
publicações de artigos e reportagens sobre o curso, criação e atualização de portais com conteúdos interativos, entre outros.

\section{METODOLOGIA DE PESQUISA}

Este estudo caracterizou-se como uma pesquisa qualitativa de cunho exploratório, inserido no paradigma interpretativista, partindo da perspectiva de que o mundo e a realidade não são objetivos ao homem, mas socialmente construídos e recebem significado a partir dele (Roesch, 2005). Adotou-se como método a Análise de Conteúdo (AC), cujos procedimentos para a coleta e o tratamento dos dados envolveram entrevistas orientadas por roteiro não estruturado e análise temático-categorial.

O caráter exploratório do estudo deveu-se à necessidade de considerar os mais diversos aspectos de um problema ou de uma situação, sendo este tipo de estudo recomendado quando há poucos conhecimentos sobre o problema a ser estudado - no caso, a falta de estudos na área de secretariado atrelada à tentativa de apreender os fatores de atratividade dos cursos (Cervo \& Bervian, 2006; Gil, 1991; Ponte, Oliveira, Moura \& Barbosa, 2007; Vieira, 2002).

Delineou-se o arcabouço amostral de forma não probabilística por julgamento. Identificaram-se os universitários com as características demandadas pela pesquisa, sendo estes os ingressantes no curso de Secretariado Executivo UFV, nos anos de 2010, 2009 e 2008, retrospectivamente.

Foram realizadas entrevistas não estruturadas e em profundidade, estabelecendo-se uma sequência de perguntas interativas que se referiam aos fatores de atratividade do curso de Secretariado Executivo, seguindo-se um roteiro para evitar que tópicos relevantes deixassem de ser abordados (Cervo \& Bervian, 2006).

O número máximo de entrevistas foi definido pelo critério da saturação, totalizando 28 entrevistas. Desse modo, a partir do momento em que diferentes conteúdos tornaram-se repetitivos e similares, a coleta de dados foi finalizada.

O exame dos dados seguiu os pressupostos da Análise de Conteúdo, enquanto campo de conhecimento que auxilia na análise do fenômeno sob investigação. Para Bardin (1994), a AC é uma proposta teórico-metodológica, com a pretensão de ultrapassar o status de simples análise para compor um campo do conhecimento. É um conjunto de técnicas de análise das comunicações, que utiliza procedimentos sistemáticos e objetivos de descrição do conteúdo das mensagens (Bardin, 1994).

Os processos da Análise de Conteúdo ocorreram então em três etapas: o recorte dos 
conteúdos, a definição das categorias analíticas e a categorização final das unidades de análise, respectivamente (Laville \& Dionne, 1999; Bardin, 1994).

Para o tratamento dos dados, foi utilizada a análise temático-categorial, técnica da AC, que trata do desmembramento do discurso em categorias, em que os critérios de escolha e de delimitação orientam-se pela dimensão da investigação dos temas relacionados ao objeto de pesquisa, identificados nos discursos dos sujeitos pesquisados (Bardin, 1994).

$\mathrm{Na}$ primeira etapa, os conteúdos coletados foram decompostos e recortados para melhor expressar suas significações. Estes elementos constituíram as unidades de registro - UR. Em seguida, foram definidas as categorias analíticas: os elementos de conteúdo foram agrupados por parentesco de sentido e organizados sob um modelo misto no qual as categorias foram selecionadas no início, mas permitindo modificações por parte da pesquisadora em função do que a análise aportasse. Finalmente, efetuou-se a terceira etapa pela análise de reconsideração da alocação dos conteúdos, possibilitando a sistematização e categorização dos fatores de atratividade do curso.

\section{ANÁLISE E DISCUSSÃO DOS FATORES DE ATRATIVIDADE DA GRADUAÇÃO}

O conhecimento de características sociodemográficas e do perfil acadêmico dos alunos contribuiu para a compreensão dos aspectos atrativos para o ingresso no curso de Secretariado Executivo Trilíngue da UFV.

Destaca-se que a idade média dos estudantes ingressantes nos anos de 2008, 2009 e 2010 é de 20 anos. Os alunos que ingressaram na universidade com 17 e 18 anos têm maior representatividade, mostrando que a maioria optou pelo curso antes de concluir o ensino médio. Apesar de $83 \%$ dos alunos afirmarem que receberam o apoio dos pais na escolha, $17 \%$ citaram que não seguiram as carreiras que os pais gostariam.

Notou-se que $75 \%$ dos alunos são mulheres e $25 \%$ homens. Cabe ressaltar que a procura pelo curso por parte dos homens foi maior no decorrer do período sob investigação. Em 2008 e 2009, 18\% dos alunos aprovados no vestibular eram homens, sendo que em 2010 a porcentagem aumentou para $23 \%$. Apesar desse aumento, a proporcionalidade entre homens e mulheres ainda difere significantemente.

Constatou-se que $85 \%$ dos alunos estão envolvidos em atividades extracurriculares como 
estágios ou atuação na Empresa Jr., confirmando a preocupação em melhor consolidar sua formação e garantir a inserção no mercado de trabalho.

As unidades de análise identificadas por meio de leitura do conjunto de textos das entrevistas foram agrupadas de acordo com o parentesco para auxiliar as discussões, sendo as categorias elaboradas após as definições das unidades de registro: grupo dos fatores ligados à instituição de ensino (IES), grupo de fatores do curso (SEC), grupo de fatores ligados ao mercado de trabalho (MER), e, grupo de fatores relacionados a motivos pessoais (PES).

No processo de escolha do curso de graduação, a tradição e o status da Universidade Federal de Viçosa foram influentes na opinião de $71 \%$ dos acadêmicos, os quais já tinham conhecimento sobre a UFV por meio de familiares, amigos ou até mesmo por morarem na cidade. Apesar de não terem sido considerados importantes por parte significativa dos alunos, os convênios que a universidade possui com instituições de ensino no exterior e o reconhecimento internacional da UFV atraíram $17 \%$ e $35 \%$ dos estudantes, respectivamente.

A infraestrutura e as instalações do campus de Viçosa foram diferenciais para atrair $53 \%$ dos estudantes. Como visto também nos estudos de Bronemann e Silveira (2004), e Miranda e Domingues (2006).

Em relação à avaliação da instituição feita pelo MEC, 60\% dos alunos foram atraídos pela preocupação com a situação do ensino no país atrelada ao reconhecimento e conceituação da UFV.

Os fatores de atratividade atrelados ao curso de Secretariado Executivo Trilíngue da UFV são aqueles possíveis de serem trabalhados mais facilmente pela Coordenação com intuito de atrair mais alunos, aumentando assim a relação de candidato por vaga que consequentemente, antecipa uma seleção para um perfil mais arrojado e preparado para o curso. Além da conceituação da UFV, $57 \%$ dos estudantes foram influenciados também pela avaliação do curso feita pelo MEC, de acordo com as diretrizes curriculares exigidas para a graduação do profissional. Todavia, notou-se que as práticas pedagógicas e o corpo docente foram pouco considerados. Dos $21 \%$ dos alunos que tinham algum conhecimento sobre o assunto, 17\% só citaram tais fatores por recordarem que foram apresentados na palestra de Secretariado Executivo Trilíngue do evento de mostra de profissões, “Graduação na UFV”, realizado pela Universidade. Do mesmo modo, a classificação dos alunos no Enade, enquanto reflexo do aprendizado dos estudantes, representou somente $7 \%$ de influência na escolha.

Outro ponto abordado foi a influência do Guia do Estudante na tomada de decisão. Dos entrevistados, $46 \%$ citaram terem sido influenciados de alguma forma pela consulta ao Guia.

Constatou-se ainda que todos os respondentes utilizaram o portal da Universidade para 
pesquisas aprofundadas ou superficiais sobre o curso. Em contrapartida, a taxa de aprovação foi pouco manifestada pelos alunos, apenas 7\% apontaram este fator como facilitador para entrarem no curso dada a baixa relação de candidatos por vaga. Os acadêmicos influenciados pelo contato com veteranos e bacharéis representaram $46 \%$ dos respondentes da pesquisa. Para $17 \%$ deles, a satisfação dos veteranos foi crucial para a escolha.

O ensino dos idiomas e a possibilidade de trabalhar com as línguas estrangeiras foram os principais fatores de atratividade do curso da UFV (71\%). Nunes (2000) defende a importância de se aprender outras línguas além do inglês, mas o ensino dos três idiomas foi determinante para a decisão de somente $10 \%$ dos estudantes. A análise dos textos demonstrou que para a maioria a característica "trilíngue" do curso tornou-se significativa quando já estavam estudando na universidade.

Para 90\% dos alunos ingressantes em 2010, a grade curricular e a multidisciplinaridade do curso foram os fatores que mais os atraíram. O fato evidencia que a profissão e o curso, aos poucos, têm sido mais reconhecidos pelos estudantes, e, o curso que antes era visto como "uma oportunidade de trabalhar com os idiomas" tem atraído o público pela identificação com a profissão.

Os estudantes que constituíram a amostra consideraram influentes na tomada de decisão os construtos ligados ao mercado de trabalho. Identificou-se que, para 75\% dos alunos, a amplitude da atuação no mercado de trabalho foi fator determinante na escolha do curso, em consonância com os resultados da pesquisa de Pereira e Forte (2006), Bronemman e Silveira (2004), Deschamps, Domingues e Mainardes (2008), e, Alfinito e Granemann (2003).

Por ser uma profissão imprescindível nos diversos setores empresariais, detectou-se que a empregabilidade, atrelada à multifuncionalidade do profissional e as chances de se conseguir emprego nas grandes empresas, influem favoravelmente na decisão do grupo. Assim como a formação do aluno, a aceitabilidade dos graduados no mercado de trabalho tem sido atrativo para $64 \%$ dos estudantes.

Quanto aos motivos pessoais, a pesquisa evidenciou que a proximidade de casa influenciou a escolha de metade dos respondentes. Em alguns casos, a escolha foi por ser a universidade mais próxima que oferecia o curso ou por residirem em Viçosa, assim como apontado nos estudos de Miranda e Domingues (2006), Bronemann e Silveira (2004), e, Deschamps, Domingues e Mainardes (2008). Não obstante, foi possível constatar que $82 \%$ dos entrevistados vieram de cidades de Minas Gerais, o que confirma a procura maior pelo curso devido à proximidade de

Revista de Gestão e Secretariado - GeSec, São Paulo, v. 5, n. 1, p 42-61, jan./abr. 2014. 
casa, sendo que apenas $18 \%$ dos alunos vieram de outros estados. Os alunos influenciados por familiares, amigos e parentes representaram $35 \%$ da amostra.

Além da influência dos pais, os alunos lembraram a influência dos professores do Ensino Médio, os quais citavam a UFV como exemplo de instituição de ensino renomada.

Verificou-se que 32\% dos alunos apegam-se à comodidade e ao conforto para tomada de decisão, alegando a possibilidade de morar em uma cidade maior quando forem atuar no mercado de trabalho. As médias salariais apresentadas na Internet, na palestra da Universidade, em jornais e revistas também foram decisivas para o público.

A segurança do campus foi manifestada pelos discentes da pesquisa. Ao discorrerem sobre o fato de o curso ser noturno e a preocupação dos pais com relação a essa questão, os alunos afirmaram que já sabiam que o campus era seguro por haver mais cursos no mesmo turno e pela vigilância da UFV. Os entrevistados (25\%) complementaram com a marcante característica da UFV de proporcionar aos estudantes de diferentes graduações cursarem disciplinas juntos, possibilitando novas amizades e conhecimento sobre outras áreas.

A fim de determinar a relevância dos construtos identificados nas entrevistas em profundidade, a Tabela 1 apresenta os fatores de atratividade seguidos de sua ordem de importância e ocorrência. Para tanto, foi feita a contagem do número de vezes em que as unidades de análise se mostraram influentes nas respostas dos 28 respondentes; agrupadas em categorias, foi possível mensurar as frequências para sua classificação.

Tabela 1 - Frequência dos fatores.

\begin{tabular}{|c|l|c|c|}
\hline CATEGORIA & \multicolumn{1}{|c|}{ FATORES DE ATRATIVIDADE } & FREQUÊNCIA & $\begin{array}{c}\text { \% OCORRÊNCIA NAS } \\
\text { 28 ENTREVISTAS }\end{array}$ \\
\hline MER & Amplitude da atuação no mercado de trabalho & 21 & 75 \\
\hline IES & Tradição e status da instituição de ensino & 20 & 71 \\
\hline SEC & Ensino dos idiomas & 20 & 64 \\
\hline MER & $\begin{array}{l}\text { Aceitação da instituição de ensino pelo mercado de } \\
\text { trabalho }\end{array}$ & 18 & 60 \\
\hline IES & Avaliação do MEC da instituição de ensino & 17 & 61 \\
\hline
\end{tabular}

Revista de Gestão e Secretariado - GeSec, São Paulo, v. 5, n. 1, p 42-61, jan./abr. 2014. 
Fatores de atratividade: abordagem sedutora para conquistar ingressos no curso de secretariado executivo

\begin{tabular}{|c|c|c|c|}
\hline MER & Empregabilidade do curso escolhido & 16 & 57 \\
\hline MER & Possibilidade de trabalhar em grandes empresas & 16 & 57 \\
\hline SEC & $\begin{array}{l}\text { Avaliação do MEC do curso oferecido pela } \\
\text { instituição }\end{array}$ & 16 & 57 \\
\hline IES & Infraestrutura da universidade & 15 & 53 \\
\hline PES & Pretensões salariais & 15 & 53 \\
\hline PES & Proximidade de casa & 14 & 50 \\
\hline SEC & Satisfação de bacharéis & 13 & 46 \\
\hline SEC & Satisfação de veteranos & 13 & 46 \\
\hline SEC & Avaliação do Guia do Estudante sobre o curso & 13 & 46 \\
\hline IES & Reconhecimento Internacional da Instituição & 10 & 35 \\
\hline PES & Influência de familiares, amigos, parentes & 10 & 35 \\
\hline PES & $\begin{array}{l}\text { Possibilidade de exercer a profissão morando em } \\
\text { cidades Grandes }\end{array}$ & 9 & 32 \\
\hline PES & Segurança no campus universitário & 8 & 28 \\
\hline PES & $\begin{array}{l}\text { Possibilidade de cursar disciplinas com alunos de } \\
\text { outros cursos/ departamentos }\end{array}$ & 7 & 25 \\
\hline SEC & $\begin{array}{l}\text { Multidisciplinaridade da grade curricular e } \\
\text { dinamismo do curso }\end{array}$ & 7 & 25 \\
\hline
\end{tabular}

Fonte: Elaborada pelos autores.

A amplitude do mercado de trabalho foi o construto mais relevante entre os demais,

Revista de Gestão e Secretariado - GeSec, São Paulo, v. 5, n. 1, p 42-61, jan./abr. 2014. 
apontado em maior número. O amplo campo de atuação do profissional da área secretarial, deste modo, influi positivamente a atração pelo curso. A classificação deste fator, bem como a aceitação da IES pelo mercado, a empregabilidade e a possibilidade de trabalhar em grandes empresas posteriormente classificados, reafirmam a preocupação dos alunos com o futuro e as chances de conseguir emprego ao final da graduação. Tal visão deve-se à concorrência com os outros profissionais, à modernização e aos avanços tecnológicos da realidade globalizada em que vivemos como constatado também nos estudos de Pereira e Forte (2006), Bronemann e Silveira (2004), Deschamps, Domingues e Mainardes (2008) e Alfinito e Granemann (2003).

A tradição e o status da Universidade Federal de Viçosa e o ensino dos idiomas no curso obtiveram a mesma representatividade nesta pesquisa, responsáveis por $71 \%$ de ocorrência nas entrevistas. A UFV, enquanto instituição de ensino renomada e reconhecida, influencia consideravelmente a escolha dos estudantes. Este fator foi também influente nos estudos de Franco (2000), Palacio, Menezes, Perez (2002), Bronemann \& Silveira (2004), Becker et al. (2004) e Deschamps, Domingues e Mainardes (2008).

Quanto à importância identificada do ensino dos idiomas, Maccari (2010) elucida sobre a necessidade do domínio de outros idiomas visando à atuação no mercado considerada a maior facilidade de comunicação com outros países. Essa realidade explica a ocorrência deste construto, caracterizando a preocupação com a formação estudantil e posterior carreira profissional. Avaliação feita pelo MEC, tanto da instituição quanto do curso de graduação teve relevância entre os demais.

Foi possível identificar que os fatores de atratividade, especialmente aqueles ligados ao curso, podem ser considerados construtos oportunos para a futura elaboração de estratégias positivas de comunicação. Além disso, por meio dos dados obtidos com a pesquisa, planos de ação instrutivos podem ser delineados, focados em construtos específicos, com intuito de elucidar a real função e atuação do profissional.

\section{CONSIDERAÇÕES FINAIS}

O objetivo deste estudo foi o de resgatar o perfil pessoal e estudantil dos estudantes e identificar os fatores de atratividade do curso de Secretariado Executivo Trilíngue da Universidade Federal de Viçosa - MG, com intuito de subsidiar estratégias de comunicação para atrair alunos de graduação.

Constatou-se que a maioria dos estudantes é jovem, formandos do ensino médio, solteiros e 
que ainda não constituíram família. Este perfil retrata a priorização na formação acadêmica do indivíduo preocupado com a carreira profissional, descrito nos três principais construtos de atratividade identificados: a situação do mercado de trabalho, a confiabilidade na universidade e o aprendizado de outros idiomas. Percebeu-se ainda, que os fatores atrativos ligados a motivos pessoais como a influência de amigos e familiares, segurança no campus e proximidade de casa foram menos relevantes.

As análises dos resultados possibilitaram inferir que a comunicação, quando utilizada de forma adequada é capaz de persuadir as pessoas. Uma explicação para a assertiva é que os alunos que participaram do evento "Graduação na UFV" apegaram-se aos aspectos positivos inerentes ao curso que foram apresentados.

Esta realidade pode ser trabalhada sob duas perspectivas: explorar a comunicação para reforçar a atração dos candidatos de cidades próximas; ou trabalhar a comunicação para despertar o interesse de estudantes de outros estados. É possível pesquisar sobre o curso de Secretariado Executivo no site da UFV ou obter informações sobre ele no evento supracitado, principais meios de publicidade da instituição, e, deste modo, para reforçar a atratividade dos vestibulandos da região, sugere-se a realização de palestras nas escolas, panfletagem e divulgação "boca a boca". Além disso, chamadas em comerciais de televisão podem ser eficazes; a própria TV Viçosa pode ser oportuna para a divulgação local.

Para a apreensão de estudantes dos demais estados, principalmente em cidades que já possuem ligação com a Universidade em função da realização do vestibular, apontam-se como estratégias a publicação de anúncios em jornais e revistas locais, a disponibilização de letreiros com informações sobre o curso e a distribuição de folhetos nas escolas e nas instituições de prévestibular.

A definição dos fatores relativos à amplitude do mercado de trabalho, a tradição e o status da Universidade como mais relevantes indicam uma possibilidade de investimento em estratégias de comunicação das relações públicas e da propaganda, trabalhando-se a linguagem verbal e não verbal na demonstração de vantagens desta graduação e o valor atribuído ao diploma da UFV em termos de empregabilidade.

Notou-se que, mesmo os alunos que não tiveram contato direto com profissionais que atuam na área para esclarecimento do mercado de trabalho, afirmaram que pesquisaram na Internet sobre as referidas profissão e graduação. Corrobora-se com Tondelli (2005) que esta rede de comunicação tem sido o meio mais utilizado pelos estudantes na busca de informações, de forma que atualizar

Revista de Gestão e Secretariado - GeSec, São Paulo, v. 5, n. 1, p 42-61, jan./abr. 2014. 
a página de Secretariado Executivo Trilíngue no portal da UFV e da Empresa Jr. de Secretariado, bem como incentivar publicações e depoimentos em blogs de Secretariado e em fóruns de discussão sobre a carreira, são alternativas que podem ampliar o reconhecimento do curso e impactar a conquista de estudantes.

A proposta de identificar fatores atrativos do curso de Secretariado Executivo contribuiu para a compreensão da comunicação como instrumento de divulgação das atividades e dos desafios para estudantes e profissionais da área. Considera-se que se mais estudantes do ensino médio e vestibulandos soubessem da existência do curso de Secretariado Executivo Trilíngue da Universidade Federal de Viçosa, poder-se-ia despertar o interesse do público por esta graduação, favorecendo a valorização do curso e o reconhecimento da profissão.

Cabe ressaltar que a pesquisa realizada não teve a intenção de esgotar as possibilidades de estudo sobre os principais fatores de atratividade desta graduação, de modo que outros estudos poderiam ser realizados para identificar estratégias de inserção dos demais aspectos na comunicação da imagem positiva do curso.

Sugerem-se como pesquisas futuras investigações sobre os motivos de atração dos alunos relacionando-os com os níveis de satisfação com o curso e estudos com os próprios vestibulandos, candidatos às vagas do curso pesquisado e/ou de outras instituições de ensino.

\section{REFERÊNCIAS}

Alfinito, S.; Granemann, S. R. (2003). Escolha de uma IES em função da utilização do usuário potencial: o estudante. In Rocha, Carlos H. \& Granemann, S. R. (orgs.). Gestão de instituições privadas de ensino superior. São Paulo: Atlas, pp. 93-103.

Bardin, L. (1994). Análise de conteúdo. Lisboa: Edições 70. (2009). Análise de conteúdo. Lisboa: Edições 70.

Becker, M.; Fornoni, M; Perfeito, J.; Silveira, A.(2004). Marketing em instituições privadas de ensino superior: fatores influenciadores na atratividade dos cursos de administração. Revista Gestão \& Tecnologia, vol. 4, pp. 83-103.

Revista de Gestão e Secretariado - GeSec, São Paulo, v. 5, n. 1, p 42-61, jan./abr. 2014. 
Bronemann, M. R. \& Silveira, A. (2004). Marketing em instituições de ensino superior: a promoção do processo seletivo. In Melo, P. A. \& Colossi, Nelson (orgs.). Cenários da Gestão Universitária na Contemporaneidade. 1a ed. vol.1, pp. 97-114. Florianópolis: Insular.

Cervo, A. L. \& Bervian, A. (2006). Metodologia científica. (5a ed.) São Paulo: Pearson Prentice Hall.

Deschamps, M.; Domingues, M. J. de S. \& Mainardes, E. W.. (2008). Fatores de atratividade de estudantes em cursos de graduação em administração. REAd: Revista Eletrônica de Administração, Porto Alegre, 61a ed, vol.14, n.3, set./dez. Recuperado em 15 setembro, 2020 de <http://www.seer.ufrgs.br/index.php/read/article/viewFile/14002/7893>.

Franco, E. (2000). Marketing educacional. Anais... Seminário Gestão de IES: da teoria à prática. Fundação Nacional de Desenvolvimento do Ensino Superior Particular. Brasília: Funadesp.

Gil, A.C. (1991). Como elaborar projetos de pesquisa. São Paulo: Editora Atlas.

Guia de Profissões. Profissões - mais de 100 cursos, n. 3, ago./2000. In Portal do Aprendiz. $\begin{array}{lllll}\text { Recuperado em } & 30 & \text { outubro, } & 2010 & \text { de }\end{array}$ <http://www2.uol.com.br/aprendiz/n_revistas/revista_profissoes/agosto00/humanas/secretariado/ index.htm>.

Hides, M. T.; Davies, J. \& Jackson, S. (2010). Implementation of EFQM excellence model selfassessment in the UK higher education sector - lessons learned from other sectors. The TQM Magazine. 2004, vol. 16, n. 3, pp. 194-201. Recuperado em 2 outubro, 2010 de <http://www.emeraldinsight.com>.

Hoeller, P. A. F. (2006). A natureza do conhecimento em secretariado executivo. Revista Expectativa, Cascavel, PR, vol.5, n. 5, pp.11-19. Recuperado em em 20 outubro, 2010 de $<$ http://erevista.unioeste.br/index.php/expectativa/issue/view/142/showToc>.

Ikeda, A. A. \&Veludo-de-Oliveira, T. M. (2010). Valor em serviços educacionais. Recuperado em 20 agosto, $2010 \mathrm{de}<$ http://www.scielo.br/pdf/raeel/v5n2/v5n2a03.pdf $>$.

Koc, E. (2006). Extended review of Shakespeare, Eisntein and the bottom line: the marketing of higher education by D.L. Kirp.OntheOrizon. (Vol. 14, n.1, pp. 19-21). Recuperado em 22 setembro, 2010 de <www.emeraldinsight.com>.

Kotler, P. \& Keller, K. L. (2006). Administração de Marketing. (12a ed.) São Paulo: Pearson. 
Kotler, P. (2009). Marketing para o século XXI: como criar, conquistar e mantermercados. São Paulo: Ediouro.

Laville, C. \& Dionne, J. (1999). A construção do saber. Belo Horizonte: UFMG.

Maccari, E.; Martins, C.; Terra, P.; Vicente, I. (2010). A formação do profissional em Secretariado Executivo nomercado de trabalho globalizado. Revista de Gestão e Secretariado - GeSec, São Paulo, vol.1, n. 1, pp. 69-89, jan./jun. Recuperado em 18 outubro, 2010 de <http://www.revistagestaoesecretariado.org.br/ojs2.2.4/index.php/secretariado/issue/current>.

Marchelli, P. S. \& Sabino, R. F. (2009). O debate teórico-metodológico no campo do secretariado: pluralismos e singularidades. Cadernos Ebape BR, Rio de Janeiro, RJ, vol.7, n.4, pp. 607-621. Recuperado em 20 out. 2010 de < www.ebape.fgv.br/cadernosebape $>$.

Miranda, C. M. S. \& Domingues, M. J. C. S. (2006). Razões para escolha de uma IES: uma abordagem sobre o perfil socioeconômico de alunos interessados em cursar Administração. In XVII ENANGRAD, São Luís. Anais... Maranhão: ENANGRAD, 2006. Recuperado em 22 outubro, 2010 de < http://home.furb.br/mariadomingues/artigos/XVII_ENANGRAD_2006/Razoes_para_Escolha_d e_Uma_IES.pdf $>$.

Moraes, L. M. M. B. L. (2005). O futuro da profissão - um mundo de oportunidades. Recuperado em 29 outubro, 2010 de <http://www.sinsesp.com.br/index.php/artigos/secretariado/27-o-futurodaprofissao-um-mundo-de-oportunidades>.

Marrou, Henri-Irénée. (1975). Introdução. In . A história da educação na antiguidade. São Paulo: EPU, pp. 1-14.

Nunes, A. (2010). Além do inglês: O terceiro idioma faz a diferença. Recuperado em 23 outubro, 2010 de <http://www.veja.abril.uol.com.br>.

Palacio, A. B.; Meneses, G. D. \& Pérez, P. J. P. (2002).The configuration of the university image and its relationship with the satisfaction of students. Journal of Educational Administration, vol. 40, n. 5, pp. 486-505. Recuperado em 2 outubro, 2010 de <http://www.emeraldinsight.com>.

Pereira, M. S. \& Forte, S. H. A. C. (2006). Visão Baseada em Recursos nas Instituições de Ensino Superior de Fortaleza: uma análise ex-ante e ex-post à LDB/96. Revista ANGRAD, vol. 7, n. 1, pp. 111-130.

Pinho, J. B. (2001). O poder das marcas. (3 ed.) São Paulo: Summus Editorial.

Ponte et al. (2007). Análise das metodologias e técnicas de pesquisas adotadas nos estudos brasileiros sobre Balanced Scorecard: um estudo dos artigos publicados no período de 1999 a 2006. In I Congresso ANPCONT, Gramado. Anais..., Gramado: ANPCONT, 2007. Recuperado em 3 novembro, 2010 de <http://www.anpcont.com.br/site/docs/congressoI/03/EPC079.pdf>.

Revista de Gestão e Secretariado - GeSec, São Paulo, v. 5, n. 1, p 42-61, jan./abr. 2014. 
Roesch, S. M. A. (2005). Projetos de Estágio e de Pesquisa em Administração - guia para estágios, trabalhos de conclusão, dissertações e estudos de caso. (3a ed.) São Paulo: Atlas.

Tondelli, M. F. (2005). A influência da língua estrangeira na empregabilidade de profissionais da área tecnológica no setor industrial: um estudo exploratório na região norte do Paraná. Dissertação (Monografia) - Universidade Tecnológica Federal do Paraná, Ponta Grossa.

Vieira, V. A. (2002). As tipologias, variações e características da pesquisa de marketing. Revista $F A E$, Curitiba, vol.5, n. 1, jan.abr., pp. 61-70. Recuperado em 2 novembro, 2010 de <http://www.mouraconsultoria.com.br/artigo/Tipologia...pdf>. 